\author{
BULETINUL INSTITUTULUI POLITEHNIC DIN IAŞI \\ Publicat de \\ Universitatea Tehnică „Gheorghe Asachi” din Iaşi \\ Volumul 67 (71), Numărul 1, 2021 \\ Secţia \\ ELECTROTEHNICĂ. ENERGETICĂ. ELECTRONICĂ \\ DOI:10.2478/bipie-2021-0002

\section{sciendo}

\title{
DIGITAL COMMUNICATION LINKS COOPERATING WITH THE ANALOG 4-20 mA STANDARD FOR MARINE APPLICATIONS
}

BY

\author{
MOSTAFA ABOTALEB ${ }^{1, *}$, JANUSZ MINDYKOWSKI ${ }^{2}$, BOLESLAW DUDOJC ${ }^{2}$ \\ and ROMUALD MASNICKI ${ }^{2}$ \\ ${ }^{1}$ Gdynia Maritime University, Doctoral School, \\ Morska 81-87, 81-225 Gdynia, Poland \\ ${ }^{2}$ Gdynia Maritime University, Faculty of Electrical Engineering, \\ Morska 81-87, 81-225 Gdynia, Poland
}

Received: March 29, 2021

Accepted for publication: July 26, 2021

\begin{abstract}
The maritime industry makes a significant contribution to the globalized economy. One of the most important parts of the maritime industry is transport. Maritime transport by ships is the dominant means of transport for industrial products and food. Modern ships are increasingly automated. A characteristic feature of automation systems is the use of distributed monitoring and control systems with large distances between field devices and controllers. Among many methods of signal transmission, both in measurement and control, the dominant role in related to continuous signals is played by the twowire 4-20 mA current standard. Despite its advantages, this standard has limitations mainly due to one-way transmission of information representing one measurement quantity. Programmable transducers are an alternative to analogue solutions. This carried out research concentrates on the full assessment of the properties of the considered methods of information transmission used so far with particular reference to the two-wire 4-20 mA standard. This assessment also takes into account the negative factors characterizing the sea-going ships, such as environmental conditions or problems resulting from the use of an isolated
\end{abstract}

*Corresponding author; e-mail: m.abotaleb@sd.umg.edu.pl

(c) 2021 Mostafa Abotaleb et al.

This is an open access article licensed under the Creative Commons Attribution-NonCommercialNoDerivatives 4.0 International License (CC BY-NC-ND 4.0). 
power grid. Additionally, a description of the available digital methods used for communication in ship automation systems will be presented. Firstly, description will be provided for HART protocol (Highway Addressable Remote Transducer), Foundation Fieldbus, Profibus PA and Modbus as communication protocols adopted by modern smart transducers as alternatives for classical analogue 4-20 mA transducers. Moreover, serial communication interfaces such as RS232, RS422 and RS485 will be discussed as means of communication between automation stations. In order to demonstrate the positive contribution for smart transmitters in measurement and control process, an experimental research has been conducted at the laboratories of Gdynia Maritime University, results of which will be discussed in detail in this article. Eventually, illustration will be provided for tank level measurement systems on a commercial ship as an example for measurement and control system mainly based on classical 4-20 mA current signal. Description will be provided for the problems associated with the system and their causes. Based on the conducted discussions, there will be recommendations of suggested solutions for such problems.

Keywords: 4-20mA standard; HART; Foundation Fieldbus; Profibus PA; Smart Transducers.

\section{Introduction}

The maritime industry has many sectors, a very important part of which is related to maritime transport. Maritime transport is carried out by various types of ships such as cruises, ferries, containers, general cargo, bulk carriers, chemical ships, oil, LPG, LNG and others. The general characteristics of the measurement and control systems in the engine room and on board for any of these ships are almost similar, except for some differences that may distinguish some ships from others depending on the type of the ship. The subject of Measurement and control systems on ships is an important topic to discuss from a technical, scientific and practical perspective (Chun-ming, 2016) in order to improve their performance in the marine environment. Sea conditions are characterized by the induction of disturbances, distortions as well as attenuation, negatively affecting the measured electrical signals used in these systems, especially when additional factors such as humidity, vibration and frequent variation of ambient temperature are taken into account (Dudojc and Mindykowski, 2019).

Sensors and transducers are used to convert measured process variables into electrical on/off signals, analogue signals, hybrid analogue signals and digital signals. Afterwards, these electrical signals are processed by host controllers such as PLCs (Programmable Logic Controllers) or by Distributed Control System (DCS). On/off sensors provide means of conversion for specific value of the process variable so that the control system can activate an alarm. Unlike on/off signals, analogue signals provide continuous conversion of measured process variable. 
Smart transducers provide a means of detection for any negative influences that might be induced by harsh environmental conditions as was previously mentioned. Hybrid analogue smart transducers such as HART transducers or digital smart transducers such as Foundation Fieldbus and Profibus PA transducers, each of them provides a specific mechanism based on which the performance of measurement and control process is continuously evaluated. Loop Characterization and Static Process Monitoring (SPM) are two examples of mechanisms adopted by programmable transducers for the purpose of deriving statistical information from the measurement process readings to detect any kind of abnormalities that might negatively affect the measurement or control process.

As an example of measurement and control systems on ships, a brief description will be provided for tank level measurement. This article will refer to such a case study in which problems associated with tank level measurement system will be analyzed in the context of being a measurement and control system mainly based on the classic analogue $4-20 \mathrm{~mA}$ standard, especially that both the transmitters and the actuators used in the system are 4-20 mA analogue devices.

\section{Two Wire 4-20 mA Analogue Standard}

Analogue measurement and control signals provide means of interpretation for the measured or controlled quantity into an electrical current or voltage standard signals. This interpretation is done by various types of transducers which differ in their measurement mechanism structure according to the measured quantity, for example temperature, pressure or flow. There are many analogue measurement and control standard signals such as $0-20 \mathrm{~mA}$, 4-20 mA, 1-5 V, 0-5 V and -10 to $10 \mathrm{~V}$ (Snyder, 2008). Among all these analogue signals, 4-20 mA signal is the most widely used due to its non-zero lower range limit (20\% offset). The $20 \%$ offset of $20 \mathrm{~mA}$ allows for the implementation of two-wire connection between the transducer and an indicator or controller.

In its simply forms of two-wire 4-20 mA current loop presented in Fig. 1 consists of analogue transducer, which actually is a controlled passive source of current (sink type), power supply from source of voltage Ups and series resistance of indicator $R_{i}$ and two cable resistances $R_{c}$. The sum of all series resistances in current loop is represented by load resistance $R_{L}$. In industry condition, the current loop presented in Fig. 1 can be named as a measurement line due to the very long distance between the transducer and the place of indication of measured quantity. The indicator resistance $\mathrm{R}_{\mathrm{i}}$ can be the internal resistance of milli-ammeter which is calibrated to the measured quantity or the internal resistance of any SCADA (Supervisory Control \& Data Acquisition System) analogue input card. 


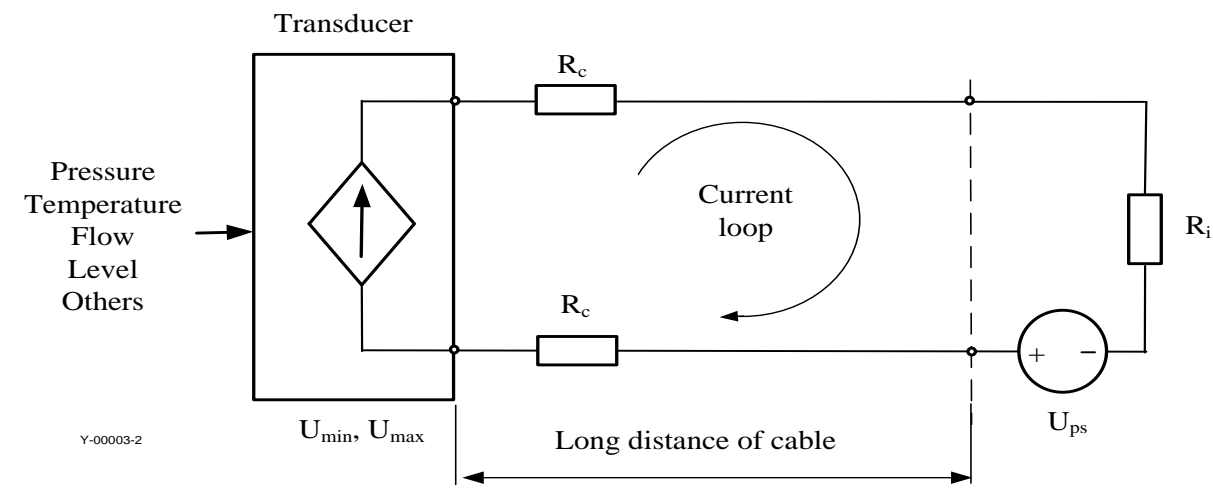

Fig. 1 - Measurement line of two-wire 4-20 mA standard.

The current loop can be supplied by external power supply or by the control system analogue input card to which the measurement line is connected. For analogue input card, the value of the resistance $R_{i}$ is dependent on the voltage analogue signal to which the 4-20 mA current signal will be converted.

Practically in the current loop, it can be connected some different indicators, analogue inputs cards or other kinds of equipment. Each of these kinds has its own input resistance. For each measurement line there is a limit for equivalent load resistance $R_{L}$ which is expressed by equation: $R_{L} \leq\left(U_{p s}-\right.$ $\left.\mathrm{U}_{\min }\right) / \mathrm{I}_{\max }$. In case was equal to $20 \mathrm{~mA}$, the equation will be $\mathrm{R}_{\mathrm{L}} \leq 0.05 \cdot\left(\mathrm{U}_{\mathrm{ps}}-\right.$ $\left.\mathrm{U}_{\min }\right)[\mathrm{k} \Omega]$. This condition can be graphically presented as illustrated in the Fig. 2 by operating region of two-wire measurement line in 4-20 mA standard.

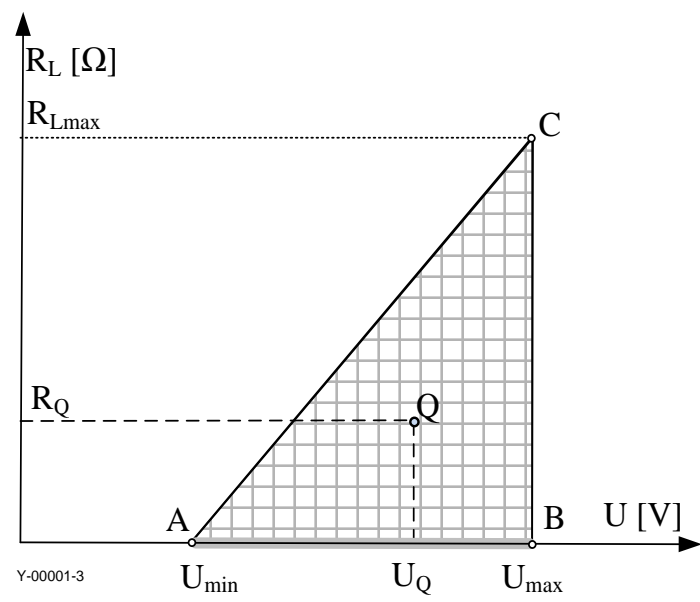

Fig. 2 - Operating region of the measurement line in 4-20 mA standard, where $U_{\min }$, $\mathrm{U}_{\max }$ are the admissible range of voltage for transducer. 
For each real two wire measurement line, only one voltage supply $\mathrm{U}_{\mathrm{Q}}$ can be used to provide the loop with power from the source of voltage $U_{\mathrm{ps}}$. The same is for equivalent load resistance $R_{Q}$ which is the sum of all resistances in loop current. The supply voltage $\mathrm{U}_{\mathrm{Q}}$ and the equivalent load resistance $\mathrm{R}_{\mathrm{Q}}$ are the coordinates of working point Q placed in the area of operating region of the measurement line (Dudojc and Mindykowski, 1996).

In such approach, the basic requirement for designer of two wire measurement lines in current 4-20 mA standard can be defined. A properly designed measurement line requires that the working point $\mathrm{Q}$ have to be inside or on the sides of the ABD triangle (Dudojc and Mindykowski, 2000).

\section{Digital Links and 4-20 mA Analogue Standard}

Digital links cooperating with 4-20 mA analogue standard will be discussed in this article from two perspectives:

- Communication protocols adopted by smart transducers:

1. HART Protocol,

2. Foundation Fieldbus,

3. Profibus PA,

4. Modbus Protocol.

- General use communication interfaces responsible for serial communication between automation stations and Input/Output modules:

1. RS232 Serial Interface,

2. RS422 Serial Interface,

3. RS485 Serial Interface.

\subsection{Communication Protocols Adopted by Smart Transducers}

\subsubsection{HART Protocol}

HART (Highway Addressable Remote Transducer) protocol transducer is a hybrid technology device which depends on superimposition of digital signal over the regular 4-20 mA analogue signal. The superimposed signal is a FSK (Frequency-Shift Keying) digitally modulated sinusoidal signal in which ones are represented by $1200 \mathrm{~Hz}$, and zeroes by $2200 \mathrm{~Hz}$ (Fig. 3). Average current of superimposed FSK signal is equal to zero. The superimposed FSK signal includes additional diagnostic information (Liptak, 2006) to improve the reliability of measurement 4-20 mA current loop (Liptak, 2012; Mackay et al., 2003; Mehta and Reddy, 2015; Frantloviu, 2009). 


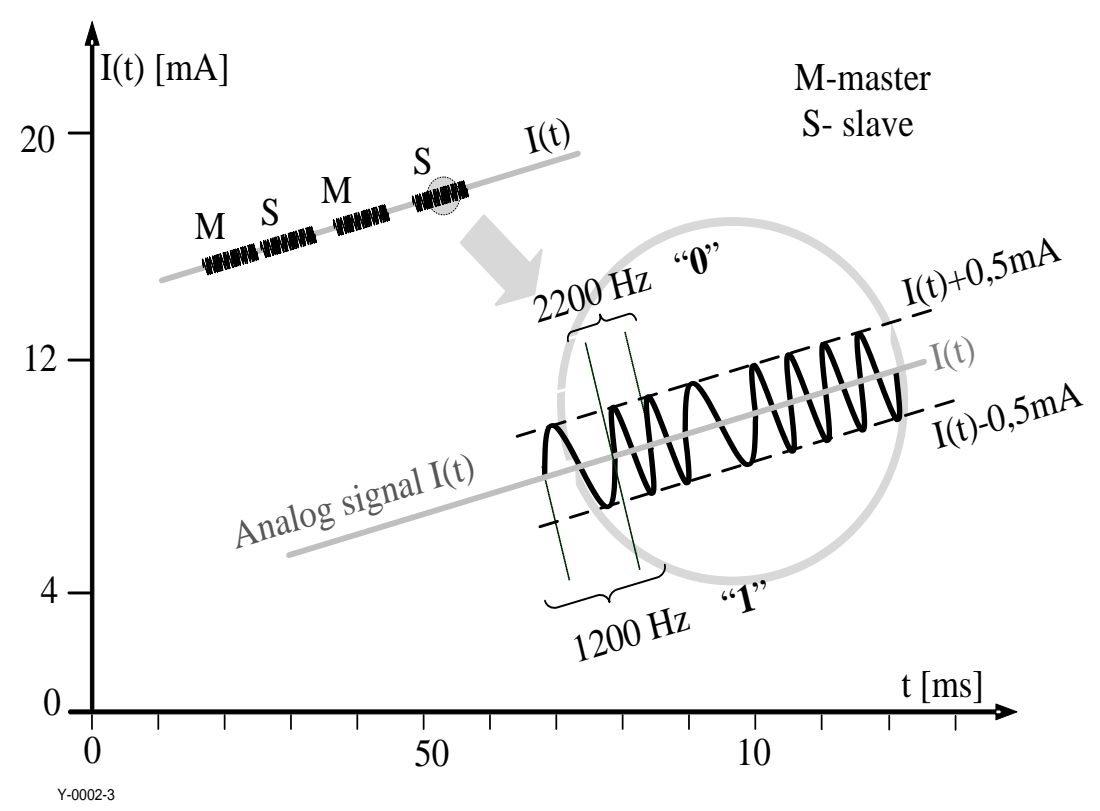

Fig. 3 - Superimposition of digital HART signal over the regular 4-20mA analogue current $\mathrm{I}(\mathrm{t})$.

HART protocol can operate in two modes, Poll/Response mode and Burst/Broadcast Mode. In Poll/Response mode, master polls the smart devices, and then one of the selected devices will start sending all the required information, Poll/Response mode is usually used with multi-drop (Berge, 2002) communication. Burst mode is a broadcasting mode in which device is continuously transmitting its information to the master with a rate of 3.7 times/s. Burst/Broadcast Mode can only be used with point to point communication (Liptak, 2012; Mackay et al., 2003; Mehta and Reddy, 2015).

Load resistance in an entire HART network should be between $230 \Omega$ and $1100 \Omega$. Load resistance of devices included in HART network can be calculated only at $20 \mathrm{~mA}$ loop current. Load resistance outside this range can increase signal attenuation and distortion, and reduce the critical transmission frequency (Liptak, 2012; Mackay et al., 2003; Mehta and Reddy, 2015; Frantloviu, 2009).

HART protocol is a master/slave protocol. Communication takes place between master and field devices through the exchange of three types of HART commands (Liptak, 2012; Mackay et al., 2003; Mehta and Reddy, 2015):

- Universal Commands;

- Common Practice Commands;

- Device Specific Commands. 


\subsubsection{Foundation Fieldbus}

Foundation Fieldbus (FF) IEC 61158 relies basically on the idea of using a single twisted pair of wires for connection of field devices. The role of field devices in the network is extended beyond the regular role of measuring process variables, as they will have the capability of performing many automation tasks. Foundation Fieldbus can also provide reliable measurement and control operations in hazardous application areas. It is a completely digital communication protocol which replaces 4-20 mA current signal with digital transmission of Manchester coded signal which includes measurement and control information as well as additional diagnostic, parameterization and fault detection information (Liptak, 2006). This additional information provided by Foundation Fieldbus is extensively more advanced than same type of information provided by HART (Liptak, 2012; Mackay et al., 2003; Mehta and Reddy, 2015; Verhappen and Pereira, 2012).

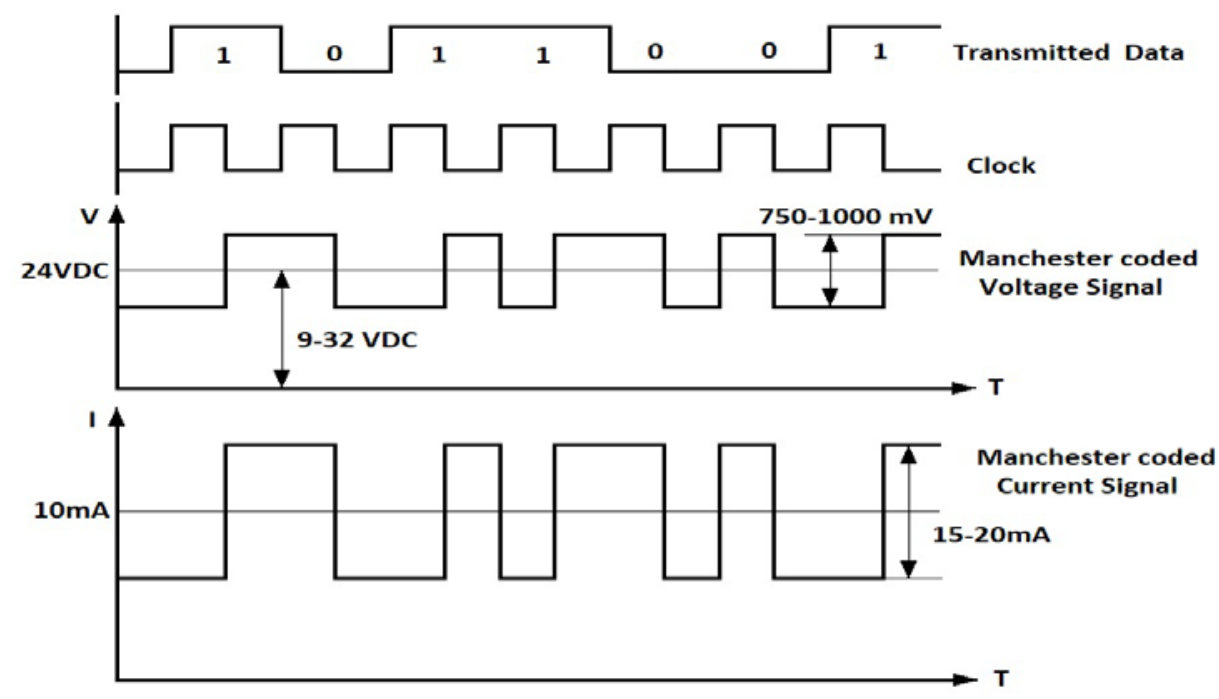

Fig. 4 - Manchester coding in Foundation Fieldbus.

Manchester coding is a modulation technique that depends on a base current signal of $10 \mathrm{~mA}$ (Fig. 4). Current will rise from $10 \mathrm{~mA}$ to $19 \mathrm{~mA}$ in case of logic " 0 " or will fall from $10 \mathrm{~mA}$ to $1 \mathrm{~mA}$ in case of logic " 1 ". These current transitions are synchronized with the system clock. The advantage of using Fieldbus devices is that loop current can be used for power supplying field devices, and the transmitted signal will never fall to the zero level. Therefore, any failure through the fieldbus can be easily detected (Liptak, 2012; Mackay et al., 2003; Mehta and Reddy, 2015; Verhappen and Pereira, 2012). 
Foundation Fieldbus uses two types of buses. First bus is relatively slow H1 (Manchester Coded Data) with a rate of $31.25 \mathrm{kbps}$, and the second one is a faster bus HSE (High Speed Ethernet) with a rate of 1 to 2.5 Mbps. $\mathrm{H} 1$ bus is used to connect all field devices to a single twisted pair of wires through spurs with a maximum length of $120 \mathrm{~m} /$ spur. Voltage across terminals of the field device should be at least 9 VDC and not more than 32 VDC (nominally 24 VDC) to ensure proper communication conditions along the field bus(Liptak, 2012; Mackay et al., 2003; Mehta and Reddy, 2015; Verhappen and Pereira, 2012).

Protocol FF adopts a distributed communication system with a network access through a deterministic, centralized management system in which LAS (Link Active Scheduler) undertakes the role of controlling and supervising the scheduled and unscheduled communication process. Unscheduled Communication is used for transaction of diagnostic data and field devices parameters. It takes place during breaks between scheduled communication intervals. Scheduled Communication can be divided into two categories, the first one is related to control and measurement variables, while the second one is related to system management (Liptak, 2012; Mackay et al., 2003; Mehta and Reddy, 2015; Verhappen and Pereira, 2012).

\subsubsection{Profibus}

There are three variants of PROFIBUS communication protocol:

1- Profibus FMS (Fieldbus Message Specification);

2- Profibus DP (Decentralized Periphery);

3- Profibus PA (Process Automation).

Profibus FMS supports communication between automation stations and programmable logic controllers with an average speed. Profibus DP main advantage is its speed and suitability for applications that requires fast response (data rate of $9.6 \mathrm{kbps}$ to $12 \mathrm{Mbps}$ ). It allows for communication between automation stations and field devices. Class- 1 master and Class- 2 master are two types of masters which are available in Profibus DP. Class- 1 master is responsible for cyclic data exchange between field devices and automation station in a specific cycle time. Class-2 master is responsible for monitoring, visualization and parameterization by data exchange with field devices in an acyclic manner. These acyclic services (Alarms, Alerts and parameters) were introduced in the extended variant Profibus DPV1 (Liptak, 2012; Mehta and Reddy, 2015; Felser, 2017; PI, 2016).

Profibus PA was designed for field devices in process automation. A Profibus PA network consists of DPM1 (Class-1 Master), DPM2 (Class-2 Master), and slave field devices. DPM1 is responsible of cyclic data exchange of information such as measured values, set points and status conditions. DPM2 is responsible of acyclic data exchange of information required during operation 
and monitoring. Slave field devices are either transmitters or actuators. They can communicate with either of these two masters only upon master's request (Liptak, 2012; Mehta and Reddy, 2015; Felser, 2017; PI, 2016).

Transmission technique in Profibus can be either RS485 with a rate of 9.6 to 12 Mbps (Profibus DP), or IEC61158-2 with a bit rate of 31.25 kbps (Profibus PA). RS485 or RS485(IS) interfaces are adopted as a transmission technology by Profibus DP, while MBP (Manchester Bus Powered) is adopted as a transmission technology by Profibus PA (Liptak, 2012; Mehta and Reddy, 2015; Felser, 2017; PI, 2016).

Profibus network field devices can be assigned addresses from 0 to 127 . Addresses are assigned to field devices through token passing and Master/Slave communication (Fig. 5) similarly to Foundation Fieldbus. Address 126 is reserved for automatic address assignment via the master to newly installed field devices. Address 127 is assigned for telegram broadcasting to all field devices. Address 0 is usually assigned to class- 1 master and addresses from 1 to 125 are usually assigned to class- 2 master and rest of other field devices, respectively (Felser, 2017).

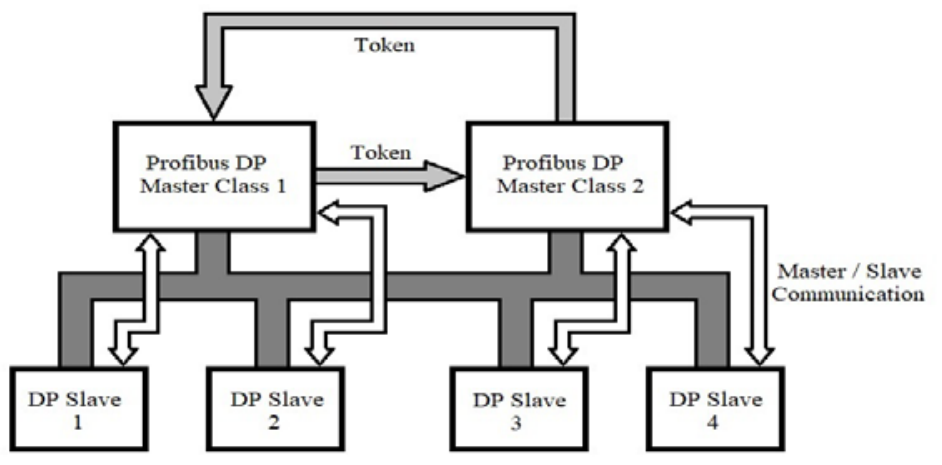

Fig. 5 - Profibus Master / Slave and Pass Token Communication.

Field devices are integrated into Profibus network through four different standards dedicated for such a purpose (Liptak, 2012; Mehta and Reddy, 2015; Felser, 2017; PI, 2016):

- General Station Descriptions (GSD).

- Electronic Device Description (EDD).

- Device Type manager (DTM) and Field Device Tool (FDT).

- Tool Calling Interface (TCI).

\subsubsection{Modbus}

Basic Modbus is aMaster/Slave (M/S) bus serial communication protocol through which a single master can communicate with up to 247 slave 
devices connected to the same bus. The master can communicate with only one slave device, or it can communicate with all slave devices through a broadcast transmission. Slave devices respond to master queries by response with the requested data only in case of communicating with one slave device, however in case of broadcast communication no response messages are provided by any of the slave devices (Modbus IDA, 20.12.2006; Modbus IDA, 28.12.2006).

There are many versions of Modbus protocol, among of which there are three versions that are the most widely used. The first two versions use the M/S as a media access control method, and the third one uses CSMA/CD method:

- Modbus RTU,

- Modbus ASCII,

- Modbus TCP/IP.

Modbus RTU (Remote Terminal Unit) is the most popular version of Modbus protocol in industrial automation as it uses CRC (Cyclic Redundancy Check) error checking mechanism which is more powerful than the mechanism LRC (Longitudinal Redundancy Check) used with Modbus ASCII. Modbus RTU uses binary coding for transmitted data while Modbus ASCII uses ASCII coding. Modbus RTU communication frame consists of 11 bits: a start bit, 8 data bits, parity bit and one stop bit. In case no parity condition was used, there will be 2 stop bits instead of one. The Modbus message consists of sequence of communication frames making up individual fields. In Modbus RTU, message frame (Fig. 6) consists of slave address, function code, up to 252 bytes and finally two CRC bytes. These frames are sent with separation intervals of at least 3.5 silent characters (Liptak, 2012; Mehta and Reddy, 2015; Modbus IDA, 20.12.2006; Modbus IDA, 28.12.2006).

In Modbus ASCII, each communication frame consists of 10 bits, a start bit, 7 data bits, a parity bit and a stop bit. In case no parity was considered, there will be 2 stop bits. As for Modbus RTU, the Modbus ASCII message frame (Fig. 9) consists of sequence of communication frames. The Modbus ASCII message frame consists of frame start (colon character ":"), slave address (2 ASCII characters), function (2 characters), data (up to 252 characters), longitudinal redundancy check (2 characters) and end of the frame (carriage return, line feed "CR, LF" characters) (Modbus IDA, 20.12.2006; Modbus IDA, 28.12.2006).

Despite differences between Modbus RTU and Modbus ASCII, both of them are serial communication protocols which share the same physical layer that might be any of serial interfaces which will be discussed later in this article RS232, RS422 and RS485 (Liptak, 2012; Mehta and Reddy, 2015; Modbus IDA, 20.12.2006; Modbus IDA, 28.12.2006). 


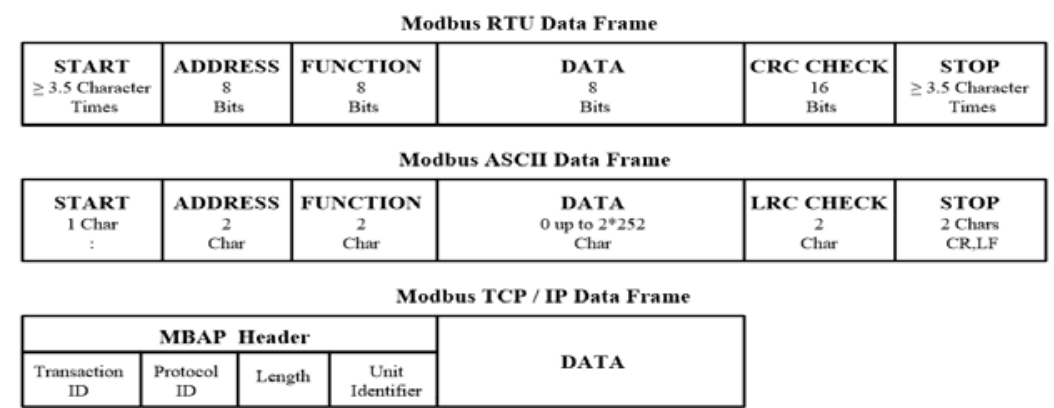

Fig. 6 - The message frame structures in Modbus different versions.

Unlike Modbus RTU and Modbus ASCII protocols, Modbus TCP/IP is a client/server protocol. Instead of addresses assigned to devices connected to the serial communication bus, Modbus TCP/IP identifies the devices in the network by their IP addresses. In Modbus TCP/IP, devices are connected through an Ethernet interface. In Modbus TCP/IP message frame, the Modbus Application Header (MBAP) (Fig. 6) replaces the slave address as well as the function and the redundancy check characters are removed. MBAP header contains all the required information to send the data to the addressed device (Liptak, 2012; Mehta and Reddy, 2015; Modbus IDA, 20.12.2006; Modbus IDA, 28.12.2006).

\subsection{Communication Interfaces Responsible for Serial Communication Between Automation Stations and Input/Output Modules}

\subsubsection{RS232 Serial Interface}

Controlled by a specific protocol, RS232 is a point to point communication interface which allows only for two devices. In RS232, data is represented in negative logic. Control signals are represented in positive logic. For negative logic, the voltage level of logic 0 is between 3VDC and 15VDC, while voltage level for logic 1 is between -15VDC and -3 VDC (Fig. 7) and vice versa for positive logic (Mackay et al., 2003; Mehta and Reddy, 2015; Sonnenberg, 2018).
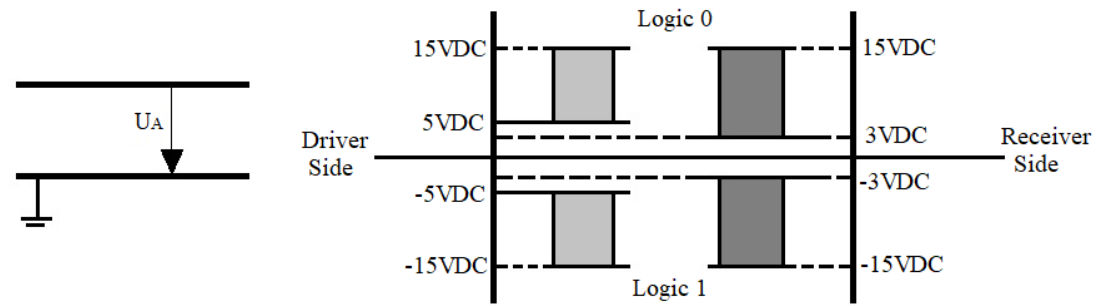

Fig. 7 - RS232 Unbalanced Voltage Signal Level. 
Data is transmitted asynchronously with a baud rate between 50 and 115 kbps. RS232 data are formatted as UART communication frames with start bit, data bits, parity bit and stop bit or bits. The voltage level of an idle RS232 bus is a negative voltage (regularly -12 VDC) (logic 1). At the beginning of transmission, transmitter sends a start bit (logic 0). Receiver will synchronize with the transmitter by the start bit and by the identical baud rate preset at both of transmitter and receiver sides. Data bits are sent after start bit with LSB firstly transmitted (Mackay et al., 2003; Mehta and Reddy, 2015; Sonnenberg, 2018).

\subsubsection{RS422 Serial Interface}

RS422 interface provides faster data transmission over longer distances than RS232. It allows for maximum number of 10 receivers to be connected in parallel with a single transmitter. Maximum allowable cable length is dependent of used data rate. For a data rate of $100 \mathrm{kbps}$, transmission line can have a maximum length of $1200 \mathrm{~m}$, while for a data rate of $10 \mathrm{Mbps}$ transmission line can have a maximum length of $15 \mathrm{~m}$. RS422 interface is a balanced to ground interface. RS422 transmitter has a signal with a voltage level of 2 to 6 VDC to express about logic 0 , and a voltage signal level from -2 to -6 VDC to express about logic 1. For logic 0 at the receiver side, the lower limit of the detected differential voltage will be $200 \mathrm{mV}$, and the upper limit will remain 6 VDC. For logic 1 at the receiver side, the lower limit of the detected differential voltage will be -6 VDC, and the higher limit will be $-200 \mathrm{mV}$ (Fig. 8) (Mackay et al., 2003; Mehta and Reddy, 2015; Marais, 2008; Sonnenberg, 2018).

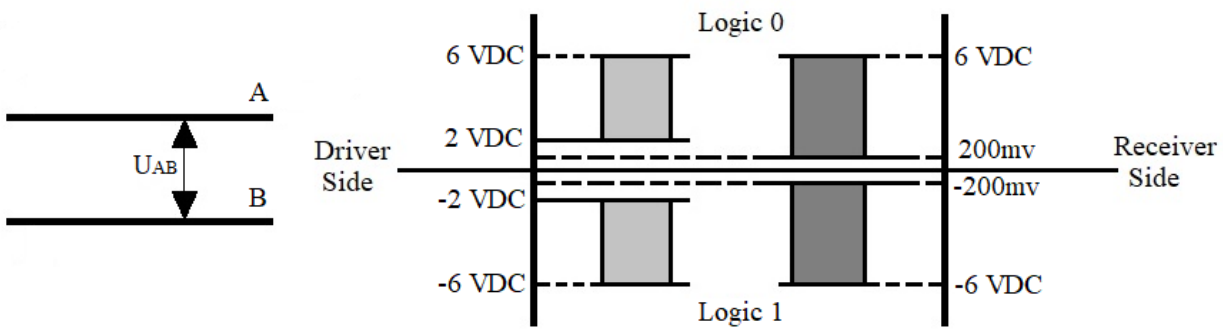

Fig. 8 - RS422 Balanced Voltage Signal Level.

In RS422 interface, transceiver can tolerate a common mode voltage up to +/-7VDC. Transmitters in RS422 interface should be able to withstand the common mode voltage when they are in the idle state. Receiver input impedance should be equal to or greater than $4 \mathrm{k} \Omega$. Termination resistors should be connected at the end of the transmission line, their values should be equal to the characteristic impedance of the transmission line (Marais, 2008; Mackay et al., 2003; Mehta and Reddy, 2015). 


\subsubsection{RS485 Serial Interface}

RS485 interface allows for up to 32 devices in half duplex or full duplex communication mode. Spacing between devices should be considered carefully to avoid impedance mismatch (Gingerich, 2006). Similarly, to RS422 interface, RS485 interface can have a maximum cable length of 15 or $1200 \mathrm{~m}$, respectively corresponding to the data rates of $100 \mathrm{kbps}$ and $10 \mathrm{Mbps}$. Signal differential voltage level for logic 0 is from 1.5 to 5 VDC and from -5 to -1.5 VDC for logic 1. RS485 drivers should be able to withstand a common mode voltage from -7 to +12 VDC (Fig. 9). Input impedance of RS485 receiver should be equal to or higher than $12 \mathrm{k} \Omega$ (Marais, 2008; Mackay et al., 2003; Mehta and Reddy, 2015; Sonnenberg, 2018).

RS485 interface usually includes distant nodes supplied by different power supply units. Therefore, there will be usually a Ground Potential Difference (GPD) between different nodes, which leads to ground current loops. In order to avoid formation of ground loops, supply isolators and signal isolators are recommended to be used with RS485 transceivers (Kugelstadt, 2008).

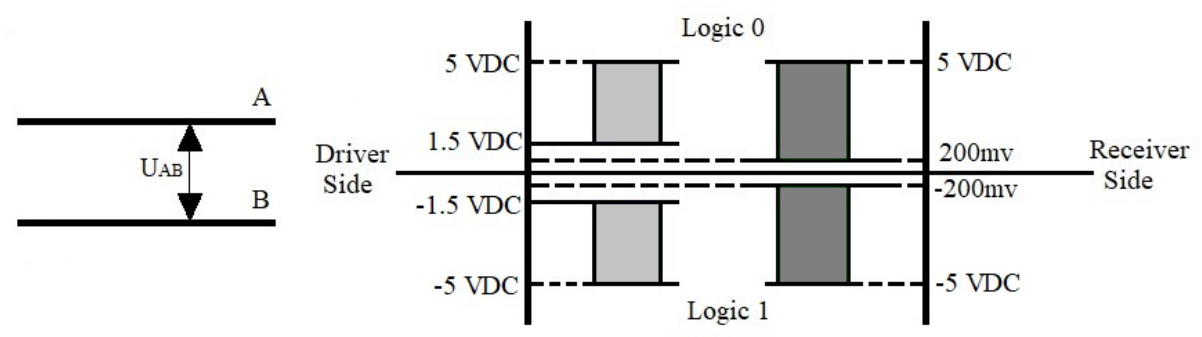

Fig. 9 - RS485 Balanced Voltage Signal Level.

Power source fluctuations, electrostatic discharge and inductive switching, any of them might be a possible cause for high levels of transient voltages which might damage RS485 transceivers. TVS diodes are used to protect transceivers by limiting spike voltages. When transient voltage is greater than TVS diode breakdown voltage, TVS diode resistance will decrease to maintain the common mode voltage at levels from -7 to +12 VDC (Marais, 2008).

\section{Experimental Research}

\subsection{Laboratory Stand and Conducted Case Studies}

An experimental research was conducted in the laboratory of the Gdynia Maritime University. It focuses on testing the 4-20 mA current loop, examined under simulated conditions. The purpose of these experiments was to 
verify the performance difference between a classical 4-20 mA measurement current loop and a smart 4-20 mA measurement current loop (HART Transmitter was used in a smart measurement loop). The sensitivity of a HART transmitter to various sources of noise was a major point of interest in comparison with a classical 4-20 mA transmitter. The way of connecting the cable shield and the way of grounding various power sources are factors that can lead to the formation of ground loops and consequently inflect a negative influence on the measurement process. The possibility of physical connection between the shield terminal and a cable terminal due to conditions such as low insulation in junction boxes caused by humidity, corrosion and vibration are also factors that was taken into account in this experimental approach.

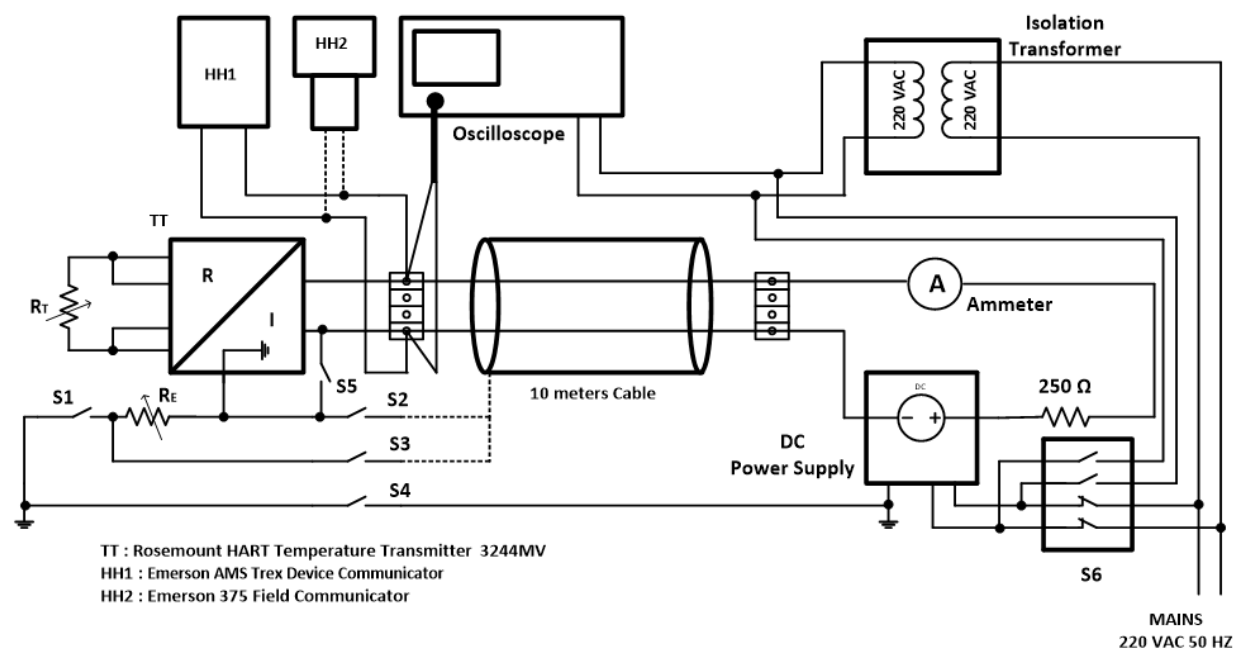

Fig. 10 - Initial Connection of 4-20 mA measurement loop at the laboratory stand.

As illustrated in Fig. 10, the current loop consists of HART smart Transmitter (Rosemount HART Temperature Transmitter 3244MV), 10 meters long of shielded twisted pair cable, DC power supply of 24 VDC, $250 \Omega$ resistance and an ammeter to measure the current flowing in the loop.

Additionally, two types of HART hand held communicators will be connected across the transmitter terminals to assess the HART communication signal of both communicators and also for comparison between both of them.

- Emerson AMS Trex Device Communicator.

- Emerson 375 Field Communicator.

The HART communication signal of each of the 2 hand held communicators will be displayed on an oscilloscope through a voltage probe connected across the two terminals of HART temperature transmitter. 
Grounding of devices of which a 4-20 mA current loop is composed, is a very important issue to consider. Generally, it is recommended for the grounding point at the transmitter side to be connected to the shield of the cable only from the transmitter side and the other side of the cable shield should be tapped and isolated in order to avoid formation of ground loops due to different potential values. This applies for both of classical 4-20 mA transmitters and also smart transmitters. Accordingly, and in order to test the negative effects caused by low insulation or improper grounding mechanisms (Induced by many causes) in the measurement 4-20 mA current loop:

- Resistor $\mathrm{R}_{\mathrm{E}}$ is connected between the grounding point of the transmitter and the earth.

- Switches S2 and S3 are used to connect the shield to various grounding points. Switch $\mathrm{S} 4$ connecting the earth point to the grounding point of the DC power supply.

- Switch S5 is used to simulate a fault condition where the shield can be connected to one of the two wires outgoing from the transmitter.

- Resistance $\mathrm{R}_{\mathrm{T}}$ is connected to the HART temperature transmitter for simulatingachange in resistance corresponding to the temperature change.

Resistance $\mathrm{R}_{\mathrm{T}}$ was adjusted to simulate a random measured temperature of $44.35^{\circ} \mathrm{C}$ which is converted to a loop current of $15.61 \mathrm{~mA}$ (measured as $15.55 \mathrm{~mA}$ by hand held communicators).

An experimental research was conducted by appropriately planned scenarios, so-called Case 1, Case 2, Case 3 and Case 4 respectively. Dedicated setups are illustrated in Fig. 11, Fig. 12, Fig. 13 and Fig. 14 respectively where the active and key elements in the given experiment are marked with grey color.

\subsection{Case 1}

For the purpose of simulating a possible attenuation or distortion source that might be induced due to improper shielding or grounding, S1, S2 and S5 were closed and resistance RE was set to zero value (Fig. 11) in order to simulate a situation that might occur due to humidified terminal strip or junction box. There was no effect on the current value in the measurement loop after closing these switches; however, the HART communication signal has suffered some slight distortion. 


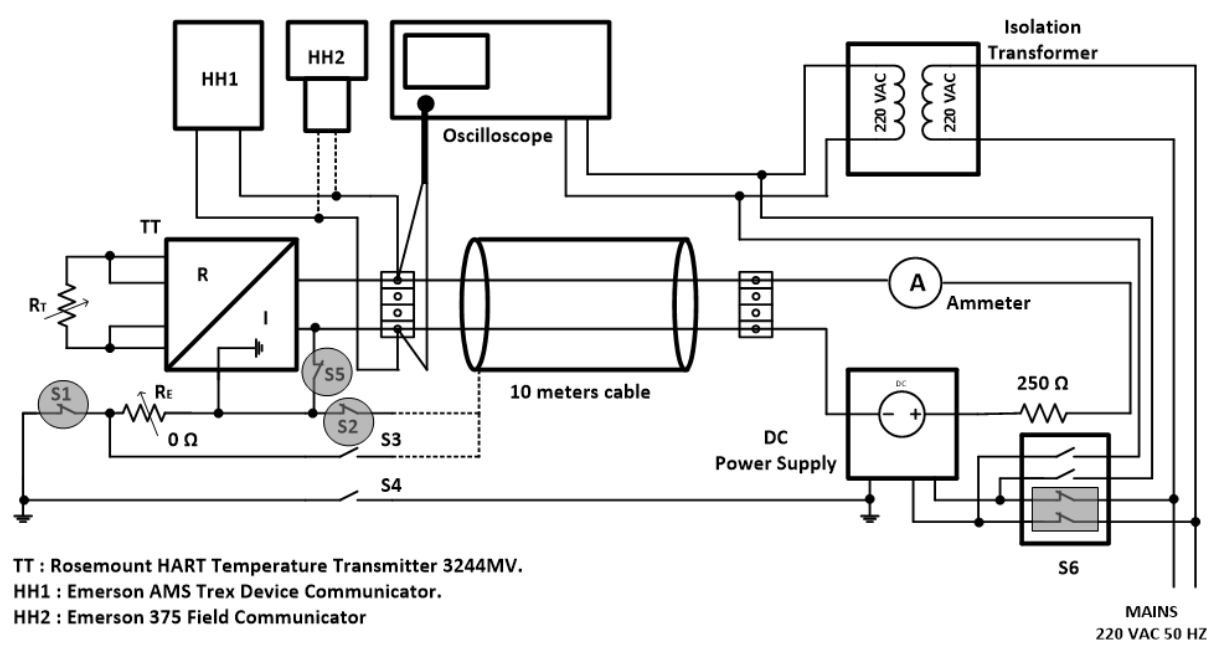

Fig. 11 - Switches S1, S2 and S5 are closed.

\subsection{Case 2}

With resistance $\mathrm{R}_{\mathrm{E}}$ set to 0 ohms, if switches $\mathrm{S} 1$ and $\mathrm{S} 5$ were closed and switch S2 or S3 started to close and open with a frequency of approximately $3 \mathrm{~Hz}$ (Fig. 12), the current value of the loop will jump from $15.61 \mathrm{~mA}$ to a value of $21.57 \mathrm{~mA}$ and sometimes up to $23.5 \mathrm{~mA}$ (this if the smart transmitter was configured to generate a high range value alarm), or it will suddenly decline from $15.61 \mathrm{~mA}$ to a value of $3.78 \mathrm{~mA}$ (this if the smart transmitter was configured to generate a low range value alarm). In addition to changing the current value in the measurement current loop, frequent switching of switches S2 or S3 also generated too many overshoots and undershoots in HART communication signal and it will eventually lead to HART communication failure if it continued for longer periods of time.An interesting fact about this frequent switching process of switches S2 and S3, is that when this switching was performed using contact points of a timer relay, the current in the loop kept its normal value of $15.61 \mathrm{~mA}$ and was not affected at all, however when this switching process was done manually by hand, overshoots and undershoots were generated and the current started to change in the loop. This leads to conclusion that HART transmitter managed to detect improper switching, the effect of which is too similar to the effect of vibration of loose or humidified terminals and also similar to the effect of reduced insulation between the shield terminal and any of the wires in the cable, which is very similar to the effects of harsh environmental conditions on any commercial ship such as vibration, corrosion and humidity. 


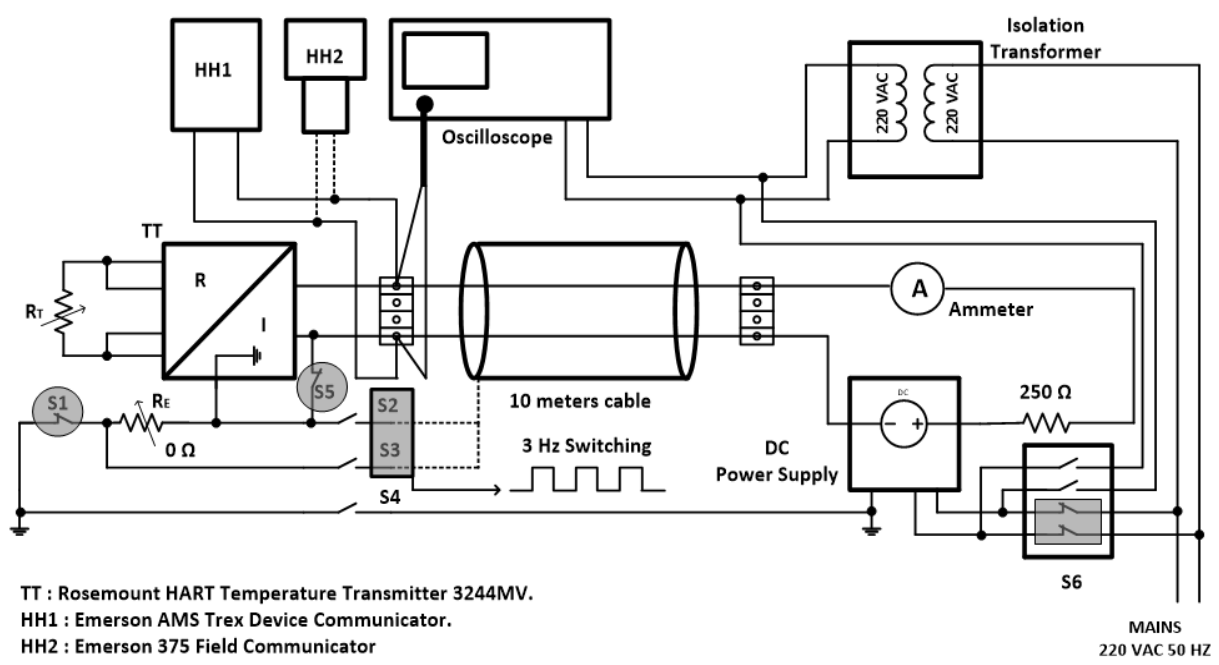

Fig. 12 - Frequent switching of switches S2 or S3.

\subsection{Case 3}

If S4 was closed and S2, S3 and S5 were open (Fig. 13), it means that grounding point of the DC power supply is united with the grounding point of the transmitter, which is normally connected to the common ground of the whole electrical system (Through closing switch S1). In such a case, hart communication signal will suffer more distortion (Overshoots and Undershoots) than the case when both grounding points of the DC power supply and the transmitter were isolated from each other.

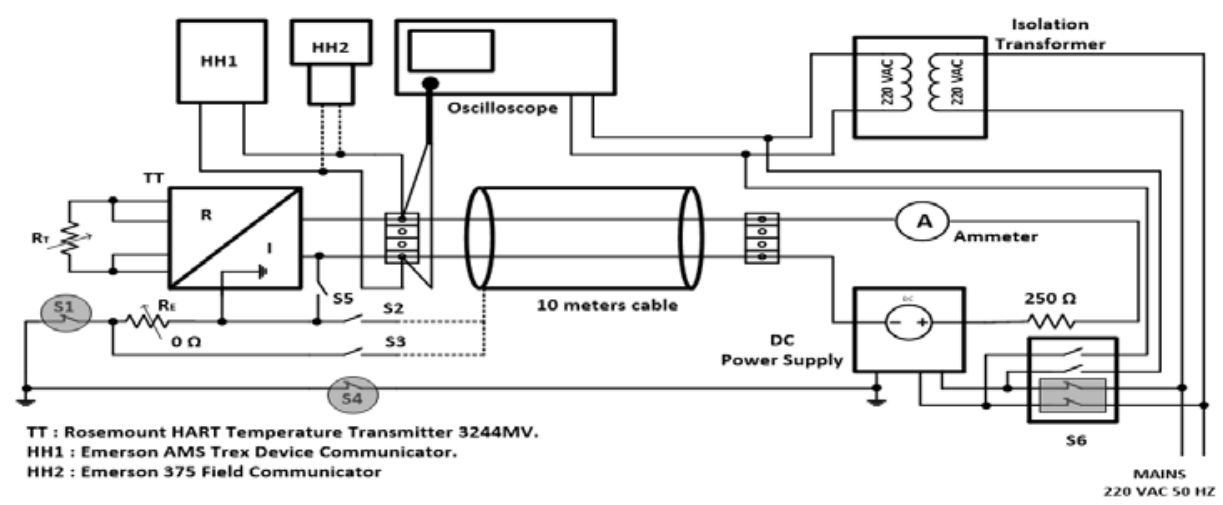

Fig. 13 - Effect of connecting grounding point of DC power supply with common ground. 


\subsection{Case 4}

In case switches $\mathrm{S} 1$ and $\mathrm{S} 5$ were closed and the resistance $\mathrm{R}_{\mathrm{E}}$ was slightly increased to the range of $100 \Omega$, then the frequent switching with an approximate frequency of $3 \mathrm{~Hz}$ was applied to both switches S2 and S3, the same effect will happen and the loop current will jump to $21.57 \mathrm{~mA}$ or fall to $3.78 \mathrm{~mA}$ depending on the configuration of the transmitter. Slightly increasing the resistance $\mathrm{R}_{\mathrm{E}}$ and applying the same frequent switching at switches $\mathrm{S} 2$ and $\mathrm{S} 3$, the same effect will be repeated until the resistance is increased to the range of (700-800 $\Omega$ ). At this moment, only frequent switching of switch S3 will cause that loop current will jump to its upper limit or fall to its lower limit, however this effect won't be generated anymore by frequent switching of switch S2 when the value of the resistance $R_{E}$ is increased more than 700 ohms. This is a very important observation which will be discussed in later research in relation with cable characteristics as well as loop and smart transmitter characteristics, especially the maximum and minimum loop resistance of the transmitter.

DC power supply is used to provide the measurement current loop with 24 VDC and it is usually powered with 220 VAC from the mains. All the previous observations were taken while the DC power supply was powered with 220 VAC from the mains, however if it was alternatively powered from the isolation transformer (as illustrated in Fig. 14) instead of the mains using switch S6, current in the loop will not be affected by any frequent switching at switches S2 or S3 and it will keep its normal value of $15.61 \mathrm{~mA}$.

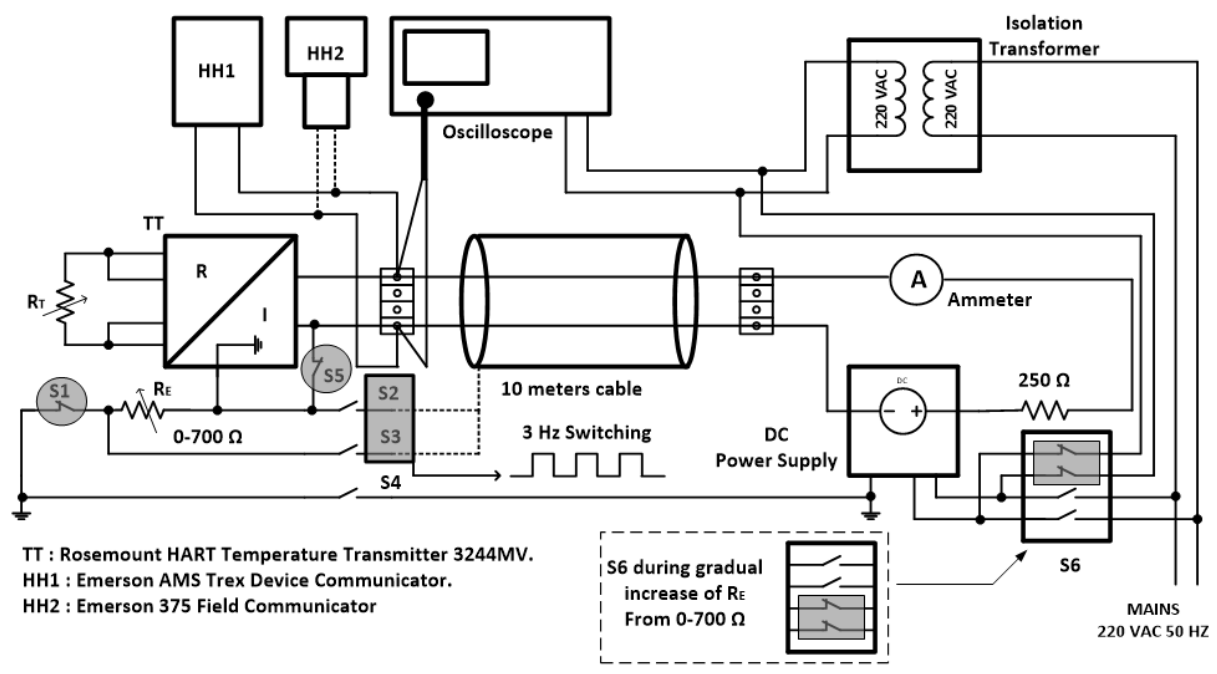

Fig. 14 - Switching AC supply from the mains to the Isolation Transformer by S6. 


\subsection{Summary of the Research}

- Unlike classical 4-20 mA transmitters, HART transmitters are more capable of early detecting the effect of environmental factors such as vibration, corrosion and humidity, which impair the continuity of transmission links and their insulation from the ship's hull, that might negatively affect the measurement and control process on the long term.

- HART transmitters can detect the effect of vibration of loose or humidified terminals by the overshoots and undershoots induced on HART communication signal because of such vibration.

- Continuity of vibration of loose, humidified or low insulated terminals in a HART 4-20 mA current loop will lead eventually to a communication failure.

- Grounding technique of different components in a HART 4-20 mA measurement current loop could be the cause of additional distortion of HART communication signal.

- Separation between the grounding point of HART transmitter and grounding point of the loop power supply is recommended to avoid additional distortion of HART communication signal.

- The resistance between the grounding point of the transmitter and the common ground of the electrical system $\mathrm{R}_{\mathrm{E}}$ should have a specific value to ensure thatthe effect of vibration of humidified terminals or corroded junction boxes can be eliminated. The technique by which this specific value of $R_{E}$ is determined will be discussed in detail in a later research.

- Different types of HART hand held communicators perform their communication tasks with field devices in different techniques, which is a subject that will be submitted to a future detailed analysis.

\section{Tank Level Measurement System on a Bulk Carrier Ship}

Tank Level Measurement System on any commercial ship, its task is to measure fluid levels in the various types of tanks on the ship. It usually performs such a task by using pressure transmitters which converts the hydrostatic pressure of the fluid inside the tank into 4-20 mA analogue input signal to the control system which will calculate the fluid level in the tank depending on its specific gravity and also depending on the tank dimensions. 


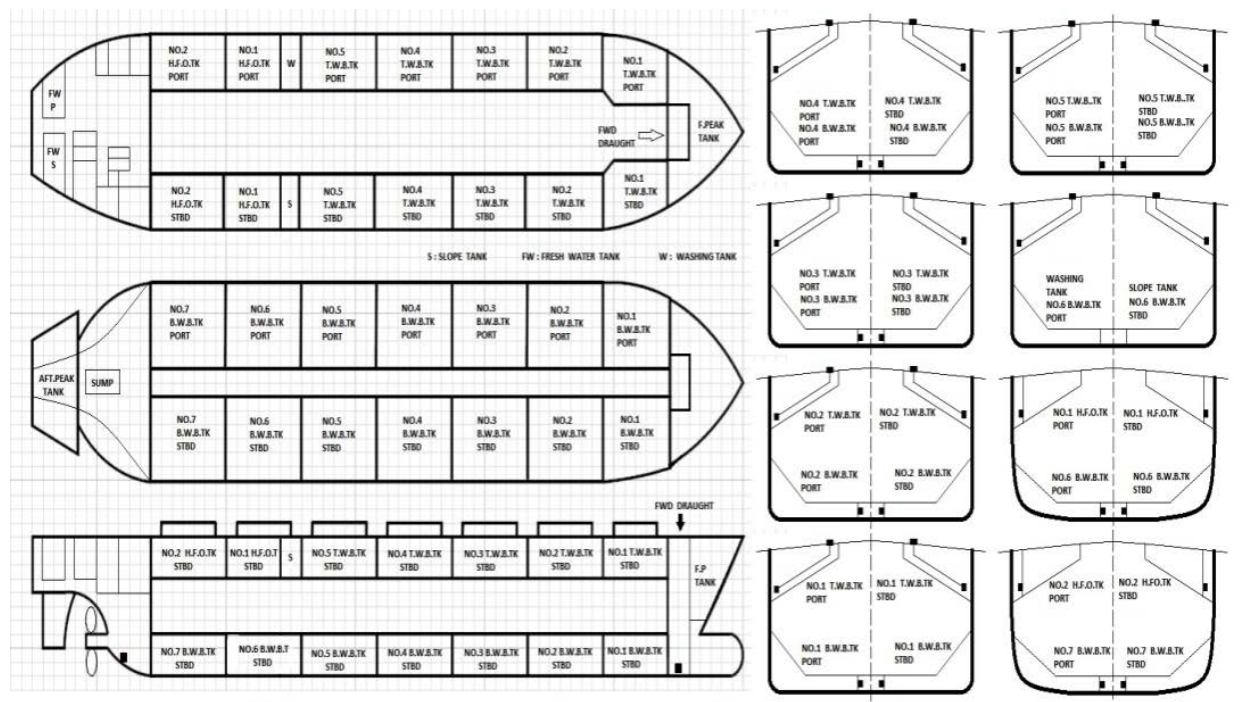

Fig. 15 - Tank level measurement system on a bulk carrier ship.

Pressure transmitters can measure the hydrostatic pressure of the fluid inside a tank, only if it was fixed at the bottom of tank, which is applicable only by using submersible transmitters which are immersed in the tank from the top to reach the bottom, or by horizontal pipe with draining valve at the bottom of the tank, and at the end of this pipe, transmitter is mounted.

In Fig.15, an example of tank level measurement system on a bulk carrier ship is illustrated. The detailed specifications of the system will be discussed in a future case study, however a brief description of the system and the problems associated with its operation and maintenance will be provided in this section. The system includes pressure transmitters to measure fluid levels in fuel oil tanks, diesel oil tanks, fresh water tanks and sea water ballast tanks. These transmitters are mounted to the tanks by using horizontal pipe or by transmitter immersion in the tank as was mentioned earlier (Fig. 16). Three main reasons lead to the most common problems associated with the operation and maintenance of the system. The first reason is the nature of the fluid in the tank, which might shorten the life time of the transmitter, which is the case with sea water ballast tanks. The second reason is the method of attaching the transmitter to the tank (Liptak, 2003; Liptak, 2017), which also might shorten the transmitter life time which is the case with immersed transmitters. The third reason is the high levels of temperature, humidity on any ship which usually leads to corrosion of junction boxes, shield terminals and grounding points and other components of measurement control loop. These problems and their effects will be discussed in detail in a future case study. Based on the theoretical and experimental background provided in this article, alternative solutions will be presented in detail in the future case study. These alternatives rely basically 
on the use of smart transducers other than classical 4-20 mA analogue transducers. These smart transducers are based on communication protocols such as HART, Foundation Fieldbus, Profibus PA or Modbus. Discussion in the case study will include differentiation between these presented solutions, and comparison between these previously mentioned digital communication protocols.

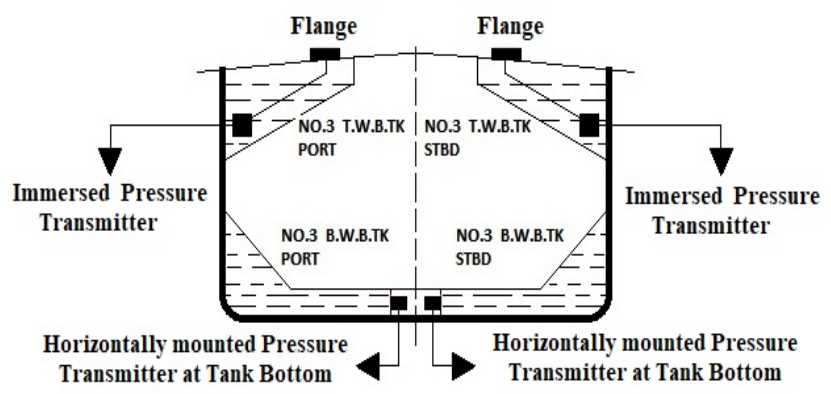

Fig. 16 - Immersed and Horizontally mounted Pressure Transmitters.

\section{Conclusion}

This article provided the basic theoretical knowledge of digital communication protocols and interfaces which exists in conjunction with 4-20 mA analogue standard. These digital means can be classified into two categories, the first category; its role is to provide the interface between the 4-20 mA current loop and the control system while the second category, its role is to replace the 4-20 mA signal carrying out measurement and control tasks. RS232, RS422 and RS485 are examples of communication links providing the interface between the 4-20 mA signal and the control system after the analogue 4-20 mA current is converted into a digital signal by analogue to digital converters. These types of interfaces are used to perform communication tasks between automation stations. The other type of protocols includes HART, Foundation Fieldbus, Profibus PA or Modbus. These protocols are presented as an alternative to the 4-20 mA current signal, as they are capable of carrying out measurement and control tasks using Hybrid Analogue or fully digital signal. Additional information (Diagnostic, Parametric and Fault detection) is included in this hybrid analogue or fully digital signal, which leads to enhancing the stability as well as the reliability of the measurement and control process. This type of protocols is the backbone of smart transducers which will be presented as an alternative solution for classical analogue transducers in a future case study.

On the other hand, the experiments described in this article show an example of the ability of smart transducers to detect different sources of noise the might negatively affect the measurement and control process. For 4-20 mA 
analogue standard, this negative influence might not be seen immediately as a change in the 4-20 mA current value, but it can be observed on the long term if these negative effects was not early detected and eliminated, and here comes the role of smart transducers such as HART transmitters providing the capability of detecting such sources of noise. These experiments also simulated the effect of loose terminals and vibration (vibration is strongly present on commercial ships) of these terminals on a smart 4-20 mA current loop. The possible connection between a cable wire and shield (Switch S5) can happen in many cases such as humidified junction boxes, high levels of corrosion in junction boxes or terminal strips, this effect added to the vibration effect might lead to the same results obtained in the experiments. The mechanism of grounding of different components of measurement current loop is also an important factor that affects the quality of the measurement process, and here comes the importance of isolators and signal conditioners. The value of the resistance between the grounding point of the transmitter and the common ground was 700 ohms, above which overshoots and undershoots in HART communication signals has stopped, which is an important point that will be subjected to a future deep analysis. Additionally, the mechanism by which different types of hand held communicators are communicating with field devices, is an important point that will be subjected to a deep analysis in a future research.

Tank level measurement system is an example of measurement and control system on a bulk carrier ship. The system is mainly based on the 4-20 mA analogue standard. High levels of temperature, vibration and corrosion are strongly present on any commercial ship, which are factors that lead to a long term deterioration of the condition of the 4-20 mA current loop. Their effects might not be detected instantaneously in a classic 4-20 mA current loop, however in a smart 4-20 mA current loop (Using HART Protocol), such an effect can be detected through its effect on the digital signal superimposed on the analogue signal. This conclusion was derived from the experiments that were presented in article. These experiments focused on simulating the possible effects of vibration, humidity and corrosion from which different components (cables, terminals \& junction Boxes) of measurement or control current loop might suffer deteriorating conditions leading to a communication failure.

\section{REFERENCES}

Berge J., Introduction to Fieldbuses for Process Control, Copyright (C) 2002 ISA - The Instrumentation, Systems, and Automation Society, ISA.

Chun-ming Z., Ru-jiang G., Dan-li W., Yan-min X., Chen Min, Jin Cheng, The Design of Bulk Carrier Cargo Holds State Integrated Monitoring System, School of Navigation, Wuhan University of Technology, Wuhan, China, MATEC Web of Conferences 61, 07014 (2016). 
Dudojc B., Mindykowski J., Analysis of Selected Properties of Measurement Channels Used in Hazardous Areas of Ships, IEEE Instrumentation and Measurement Technology Conference, Brussels, Belgium, 1996, IMTC Proceedings, Volume II, 826-831.

Dudojc B., Mindykowski J., Checking Current Analog Measurement Channels, Proc. of the IMEKO TC-4 Conference, Vienna, 2000, 175-180.

Dudojc B., Mindykowski J., New Approach to Analysis of Selected Measurement and Monitoring Systems Solutions in Ship Technology, Sensor 2019 (8), 1775.

Felser M., PROFIBUS Manual, Edition 1.2.4 published at 25. August 2017.

Frantloviu M.P., Jovanov V.J., MiljkoviüB L.J., Intelligent Industrial Transmitters of Pressure and Other Process Parameters, Telfor Journal, Vol. 1, No. 2, 2009.

Gingerich K., Device Spacing on RS-485 Buses, Texas Instruments Analog Applications Journal, 2Q 2006.

Kugelstadt T., The RS-485 Design Guide, Application Report SLLA272C-February 2008-Revised May 2021, Texas Instruments, Copyright (C) 2021, Texas Instruments Incorporated.

Liptak B.G., Halit E., Instrument Engineers’ Handbook, Process Software and Digital Networks Volume III, $4^{\text {th }}$ Edition, International Society of Automation, CRC Press Taylor and Francis Group (C) 2012, 578-635.

Liptak B.G, Instrument Engineers' Handbook, Process and Control Optimization Volume II, $4^{\text {th }}$ Edition, International Society of Automation, CRC Press Taylor and Francis Group (C) 2006, 561-574, 690-692, 780-784

Liptak B.G., Instrument Engineers' Handbook, Process Measurement and Analysis Volume I, $4^{\text {th }}$ Edition, International Society of Automation, CRC Press Taylor and Francis Group (C) 2003, 549-554

Liptak B.G., Vinczel K., Instrument and Automation Engineers' Handbook, Measurement and Safety Volume $I, 5^{\text {th }}$ Edition, International Society of Automation, CRC Press Taylor and Francis Group (C) 2017, 1171-1177, 18831888

Mackay S., Wright E., Park J., Practical Data Communications for Instrumentation and Control, $1^{\text {st }}$ edition, 11 June 2003, 3-67, 205-238, 240-287.

Marais H., RS-485/RS-422 Circuit Implementation Guide, AN-960 Application Note, 2008.

Mehta B.R., Reddy Y.J., Industrial Process Automation Systems Design and Implementation, Butterworth-Heinemann is an imprint of Elsevier, Copyright (C) 2015 Elsevier Inc.16-20, 306-339, 365-415.

Snyder D.A., Understanding 4 to 20 mA Loops, PDH Course E271, PE, 2008.

Sonnenberg J., Serial Communications RS232, RS485, RS422, Copyright 2018.

Verhappen I., Pereira A., Foundation Fieldbus, Fourth Edition, International Society of Automation; 4th edition (February 29, 2012)

** Modbus IDA, Modbus Application Protocol Specification, V1.1b, Modbus IDA, December 28, 2006.

** Modbus IDA, Modbus Over Serial Line Specification and Implementation Guide V1.02, Modbus.org, Dec 20, 2006.

** PROFIBUS \& PROFINET International (PI), PROFIBUS System Description Technology and Application, Version April 2016. 


\title{
LEGĂTURI DE COMUNICARE \\ DIGITALĂ CE COOPEREAZĂ CU STANDARDUL ANALOG 4-20 mA ÎN APLICAȚII MARITIME
}

\author{
(Rezumat)
}

Industria maritimă aduce o contribuție semnificativă la economia globalizată. Una dintre cele mai importante părți ale industriei maritime este transportul. Transportul maritim cu nave este mijlocul de transport dominant pentru produse industriale și alimente. Navele moderne sunt din ce în ce mai automatizate. O trăsătură caracteristică a sistemelor de automatizare este utilizarea sistemelor de monitorizare și control distribuite cu distanțe mari între dispozitivele de teren și controlere. Dintre numeroasele metode de transmisie a semnalului, atât pentru măsurare, cât și pentru control, rolul dominant în ceea ce privește semnalele continue este jucat de standardul de transmisie în curent 4-20 mA cu două fire. În ciuda avantajelor sale, acest standard are limitări datorate în principal transmiterii unidirecționale a informațiilor reprezentând o mărime de măsurare. Traductoarele programabile sunt $\mathrm{o}$ alternativă la soluțiile analogice. Acest studiu se concentrează pe evaluarea completă a proprietăţilor metodelor considerate de transmitere a informațiilor utilizate până acum, cu referire în special la standardul cu două fire 4-20 mA. Această evaluare ia în considerare și factorii negativi care caracterizează navele maritime, cum ar fi condițiile de mediu sau problemele rezultate din utilizarea unei rețele electrice izolate. În plus, va fi prezentată o descriere a metodelor digitale disponibile utilizate pentru comunicare în sistemele de automatizare a navelor. În primul rând, va fi furnizată descrierea protocolului HART (Highway Addressable Remote Transducer) şi apoi a celor de tip Foundation Fieldbus, Profibus PA și Modbus ca protocoale de comunicare adoptate pentru traductoarele inteligente moderne ca alternative pentru traductoarele analogice clasice cu ieşire de 4-20 mA. Mai mult, interfețele de comunicații seriale precum RS232, RS422 și RS485 vor fi discutate ca mijloace de comunicare între stațiile de automatizare. Pentru a demonstra contribuția pozitivă a transmițătoarelor inteligente în procesul de măsurare și control, a fost efectuată o cercetare experimentală în laboratoarele Universității Maritime Gdynia, ale cărei rezultate vor fi discutate în detaliu în acest articol. În cele din urmă, vor fi oferite ilustrații pentru sistemele de măsurare a nivelului rezervorului de pe o navă comercială, ca exemplu pentru sistemul de măsurare şi control bazat în principal pe semnalul de curent clasic de 4-20 mA. Va fi furnizată descrierea problemelor asociate cu sistemul și cauzele acestora. Pe baza discuțiilor purtate, vor fi recomandate soluții pentru rezolvarea unor astfel de probleme. 